\title{
Uso do penetrômetro eletrônico na avaliação da resistência do solo cultivado com cana-de-açucar ${ }^{1}$
}

\author{
Antonio M. laia ${ }^{2}$, João C. S. Maia ${ }^{3}$ \& Michely E. Kim ${ }^{4}$
}

\begin{abstract}
RESUMO
Este trabalho teve como objetivo avaliar a resistência do solo a penetração, por meio de um penetrógrafo eletrônico de velocidade constante, em dois solos: Latossolo Vermelho distrófico Típico, textura argilosa e Latossolo Vermelho Amarelo distrófico Típico, textura média, submetidos aos processos de mecanização e transporte na cultura de cana-de-açúcar, em função de diferentes números de corte e diferentes profundidades de trabalho. Os dados foram analisados estatisticamente sob dois formatos: (a) pela estatística convencional, comparando-se as médias dos tratamentos pelo teste de Tukey a 5\% de probabilidade e (b) pela geoestatística, utilizando-se a semivariância para produzir modelos que representassem dependência espacial dos dados. Os resultados de resistência do solo a penetração, mostraram-se diferenciados nas profundidades estudadas, indicando que o peso dos veículos e máquinas e a pressão dos rodados provocaram alterações no perfil do solo.
\end{abstract}

Palavras-chave: compactação do solo, mecanização, geoestatística

\section{Use of an electronic penetrometer to evaluate resistance of a soil cultivated with sugarcane ${ }^{1}$}

\begin{abstract}
This work aimed to evaluate soil resistance to penetration by means of a constant-speed electronic penetrograph, in two soils: a clay-textured Rhodic Haplustox and a loamy-textured Typic Haplustox, under mechanization and transportation processes in a sugarcane crop as a function of different numbers of cuts and different working depths. The data were statistically analyzed under two formats: (a) by means of conventional statistics, in which the treatment means were compared by Tukey test at $5 \%$ probability level, and (b) by geostatistical analysis, in which semivariance was used to produce models that would represent the spatial dependence of the data. The resistance to penetration results showed distinct behaviors for the studied depths, indicating that the weight of vehicles and machinery and the rotating wheel pressure caused alterations in the soil profile.
\end{abstract}

Key words: soil compaction, mechanization, geostatistics

${ }^{4}$ Eng. Agrônoma. Fone: (65) 8404-1834. E-mail: michelykim@yahoo.com.br 


\section{INTRODUÇÃO}

Mato Grosso participa com 3,8\% da produção nacional de cana-de-açúcar, sendo uma das regiões do Brasil que comportam a expansão da atividade devido à grande disponibilidade de terras agricultáveis e clima favorável. A tecnologia de produção tem acompanhado as evoluções, no que se refere à utilização de máquinas e implementos e técnicas de manejo e transporte. Para tanto, faz-se a opção por veículos de maior capacidade unitária de carga, os quais trafegam nas áreas de plantio, provocando a compactação do solo.

Rosolem (1994) observou que a raiz não responde à compactação do solo mas, sim, a resistência do solo a penetração (RSP), da qual a compactação é um dos fatores. A RSP depende da densidade, da umidade e da textura do solo. A impedância física de formação de novas raízes pode prejudicar o desenvolvimento das plantas. Conforme Letey (1985) e Weaich et al. (1992) a resistência do solo a penetração é um dos atributos físicos do solo que influenciam diretamente o crescimento das raízes e a parte aérea das plantas.

A caracterização da camada compactada e do comportamento do solo em relação às suas propriedades físicas, como densidade, porosidade, umidade e capacidade de retenção e infiltração da água e, principalmente, a localização da camada compactada hardpans, é de extrema significância para o planejamento das técnicas modernas de produção.

Devido a esses fatos, o desenvolvimento de sensores que meçam com precisão a compactação e de técnicas que produzam mapas de resistência do solo, é de elevada importância para as operações de preparo e utilização do solo.

Vários são os tipos de penetrógrafos, variando desde os que funcionam por impacto até os mais modernos, constituídos de células de carga e programas computacionais que proporcionam melhor funcionabilidade e precisão nos dados coletados.

Para a confecção dos mapas é conveniente entender a natureza da variabilidade espacial do parâmetro e como mapeálo. Um dos aspectos mais importantes é a quantidade de dados requerida, de forma que os mesmos possam definir se são contínuos no espaço e qual a natureza desta variabilidade.

As análises estatísticas clássicas que sempre trataram os solos como meio homogêneo, estão sendo substituídas por análises que levam em consideração as correlações entre observações vizinhas. Essas análises são possíveis graças aos grandes avanços computacionais de análise e modelagem que agora estão sendo aplicados na pesquisa de engenharia agronômica. A teoria das variáveis locais, denominada geoestatística, é uma ferramenta que possibilita estudar a variabilidade espacial das propriedades do solo.

Ante o exposto, esta pesquisa teve como objetivo avaliar a resistência do solo a penetração, em dois tipos de solo submetidos ao cultivo com a cultura da cana-de-açúcar, por meio de um penetrômetro eletrônico de velocidade constante.

\section{MATERIAL E MÉTODOS}

O presente trabalho de pesquisa foi desenvolvido em áreas cultivadas com cana-de-açúcar, pertencentes à Destilaria de Álcool Libra Ltda., localizadas na MT 010, km 50, município de São José do Rio Claro, MT. O clima caracterizase como do tipo Aw, de acordo com a classificação de Köppen (1948). Todas as análises físico-químicas foram realizadas no Laboratório de Solos da Faculdade de Agronomia e Medicina Veterinária FAMEV/UFMT.

O trabalho foi instalado no mês de setembro de 2.000, em dois tipos de solo caracterizados segundo EMBRAPA (1999) como sendo: Latossolo Vermelho distrófico Típico, textura argilosa, e Latossolo Vermelho Amarelo distrófico Típico, textura média, com declividade menor que 3\%, apresentando grande homogeneidade nos locais dos tratamentos.

Foram escolhidas quatro áreas, duas com textura argilosa e duas com textura média, todas cultivadas com canade-açúcar da variedade SP71-1406, com espaçamento de $1,40 \mathrm{~m}$ entre linhas, em regime de dois e quatro cortes. $\mathrm{O}$ experimento constituiu-se de quatro tratamentos, em delineamento inteiramente casualizado, com 15 repetições, em arranjo fatorial de 2 × 2 × 10, sendo dois tipos de solo, dois níveis de corte e dez profundidades. Os tratamentos estudados foram: tratamento 1: solo textura argilosa, 2 cortes; tratamento 2: solo textura argilosa, 4 cortes; tratamento 3: solo textura média, 2 cortes e tratamento 4: solo textura média 4 cortes.

Cada tratamento foi constituído de 15 entrelinhas espaçadas a $1,40 \mathrm{~m}$ e de 15 pontos em cada linha, distantes $1 \mathrm{~m}$ entre si, somando 225 pontos de amostragem para cada tratamento, totalizando uma área de $315 \mathrm{~m}^{2}$.

Para caracterização dos solos foram coletadas, ao acaso, cinco amostras de cada tratamento, nas profundidades de 0 a $15 \mathrm{~cm}, 15$ a $30 \mathrm{~cm}$ e 30 a $45 \mathrm{~cm}$, em pontos eqüidistantes na área de cada tratamento, nas quais foram realizadas análises físicas utilizando-se a metodologia do densímetro, conforme EMBRAPA (1997).

Para os trabalhos de coleta de dados de resistência do solo a penetração (RSP), usou-se um penetrógrafo com sensor de profundidade e de força, com capacidade de até $1.500 \mathrm{~N}$.

Para a análise convencional tomou-se cada linha como repetição, em que a média dos 15 pontos em cada profundidade de cada linha se constituiu o valor da repetição. Em cada ponto foram tomadas medidas de resistência do solo a penetração, de 0 a $50 \mathrm{~cm}$, e os dados registrados a cada $2,5 \mathrm{~mm}$, porém os valores utilizados para análise foram os valores pontuais a cada $5 \mathrm{~cm}$ de profundidade, totalizando 10 medidas por ponto, já para determinação da umidade, em cada ponto, foram coletadas amostras, no mesmo dia e sob as mesmas condições, em três profundidades diferentes: 0 a $15 \mathrm{~cm}, 15$ a $30 \mathrm{~cm}$ e 30 a $45 \mathrm{~cm}$, com o auxílio de um perfurador de solo de $40 \mathrm{~cm}$ de diâmetro e $70 \mathrm{~cm}$ de comprimento acoplado a um trator. Fezse uma trincheira e posteriormente, com uma pá reta, retirouse parte da face da parede da trincheira e com uma ferramenta construída em aço inox e com cabo graduado a cada $15 \mathrm{~cm}$, coletaram-se as amostras que foram imediatamente colocadas em copos plásticos hermeticamente fechados, condicionados em uma caixa térmica e levados ao laboratório onde o teor de umidade foi determinado pelo método da estufa.

Para caracterização dos tipos de solo em função dos máximos níveis de compactação, determinaram-se as curvas de 


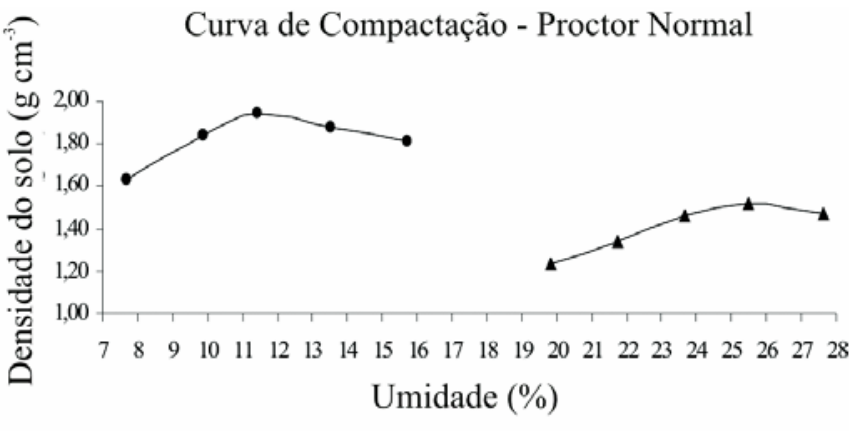

- Solo de textura argilosa $\multimap$ Solo de textura média

Figura 1. Curva de compactação dos solos textura argilosa e textura média

acordo com metodologia NBR 7182 (ABNT), para o ensaio de Proctor Normal, conforme a Figura 1.

Para a análise de geoestatística consideraram-se os 225 pontos para os 10 níveis de profundidade.

O tratamento estatístico clássico envolveu a análise de variância e o teste de média; compararam-se as médias de RSP entre os tratamentos pelo teste de Tukey a nível de 5\% de probabilidade e realizou-se a estatística descritiva: média; desvio padrão; erro padrão da média; coeficiente de variação, realizado por meio do aplicativo SISVAR (Ferreira, 2000).

O comportamento dos dados de RSP nas diferentes profundidades foi associado às suas posições nas áreas amostradas. Para identificação da dependência espacial utilizouse a função semivariância, expressa pela Eq. 1:

$$
\mathrm{Y}(\mathrm{h})=\frac{1}{2} \mathrm{~N}(\mathrm{~h}) \times \sum\left[\mathrm{Z}\left(\mathrm{x}_{\mathrm{i}}\right)-\mathrm{Z}\left(\mathrm{x}_{\mathrm{i}}\right)-\mathrm{Z}\left(\mathrm{x}_{\mathrm{i}}\right)\right]^{2}
$$

em que:

Y(h) - semivariância

$\mathrm{N}(\mathrm{h})-\mathrm{n}^{\mathrm{o}}$ de pares de observações

$\mathrm{Z}(\mathrm{xi}) ; \mathrm{Z}(\mathrm{xi}+\mathrm{h})$ - coordenadas dos pontos.

$\mathrm{h}$ - distância entre os pares de observações $(\mathrm{x}+\mathrm{h}), \mathrm{x}$.

Os modelos geoestatísticos foram selecionados por meio da relação (e) que representa o componente aleatório da de- pendência espacial entre o efeito pepita $\left(\mathrm{C}_{0}\right)$ e o componente C, conforme a Eq. 2:

$$
\mathrm{e}=\frac{\mathrm{C}_{0}}{\mathrm{C}}
$$

em que:

e - erro admissível do componente aleatório

$\mathrm{C}_{0}$ - efeito pepita

C - componente da variância da população.

Os modelos para a geração de mapas de RSP foram escolhidos conforme o critério de e $<0,5$. Para a elaboração dos mapas utilizou-se o software Surfer e, para a análise geoestatística dos semivariogramas o software Variowin.

Para avaliação do ensaio pela estatística convencional foi aplicado o teste de médias e na geoestatística, o georreferenciamento dos dados, em função do ajuste de modelos de semivariogramas.

\section{RESULTADOS E DISCUSSÃO}

Na Tabela 1 estão listados os resultados da RSP, com seus respectivos coeficientes de variação; ao se comparar as médias dos valores obtidos na profundidade de $5 \mathrm{~cm}$, foi possível detectar, por meio do teste de Tukey em nível de 5\% de probabilidade, diferenças estatísticas significativas, em que o tratamento 1 apresentou a maior média de valores $(4,63 \mathrm{MPa})$ e o tratamento 4 , o menor valor $(0,56 \mathrm{MPa})$.

Os tratamentos 2 e 3 não diferiram estatisticamente pelo teste de Tukey em nível de 5\%; o tratamento 4 apresentou o menor valor de RSP (0,56 MPa), provavelmente por possuir maior teor de areia que o tratamento 3 ou uma movimentação do solo provocada por cultivo na camada superficial.

Na camada de 0 a $5 \mathrm{~cm}$, os valores médios de RSP tenderam a apresentar uma variação muito grande, sem dúvida por ser a mais influenciada pelo tráfego de máquinas em função de sua mobilização, o que pode ser comprovado pelo valor do coeficiente de variação que, em todos os tratamentos, apresentou valores acima do ideal. Segundo Pimentel (1987),

\begin{tabular}{|c|c|c|c|c|c|c|c|c|c|c|c|c|}
\hline \multirow{4}{*}{$\begin{array}{c}\text { Profundidade } \\
5\end{array}$} & \multicolumn{12}{|c|}{ Tratamento** } \\
\hline & \multicolumn{3}{|c|}{1} & \multicolumn{3}{|c|}{2} & \multicolumn{3}{|c|}{3} & \multicolumn{3}{|c|}{4} \\
\hline & \multicolumn{2}{|c|}{ Média* } & \multirow{2}{*}{$\begin{array}{c}\text { CV } \\
47,50\end{array}$} & \multicolumn{2}{|c|}{ Média* } & \multirow{2}{*}{$\begin{array}{c}\text { CV } \\
37,37\end{array}$} & \multicolumn{2}{|c|}{ Média* } & \multirow{2}{*}{$\begin{array}{c}\text { CV } \\
37,07\end{array}$} & \multicolumn{2}{|c|}{ Média* } & \multirow{2}{*}{$\begin{array}{c}\text { CV } \\
22,87\end{array}$} \\
\hline & 4,63 & $\mathrm{Ab}$ & & 2,29 & $\mathrm{Ba}$ & & 1,12 & $\mathrm{Cd}$ & & 0,56 & $\mathrm{Dd}$ & \\
\hline 10 & 5,79 & $\mathrm{Aa}$ & 35,77 & 2,39 & $\mathrm{Ba}$ & 31,81 & 1,92 & $\mathrm{Bc}$ & 33,04 & 1,03 & $\mathrm{Cd}$ & 27,02 \\
\hline 15 & 4,71 & $A b$ & 29,89 & 2,32 & $\mathrm{Ba}$ & 37,14 & 2,42 & Babc & 30,63 & 1,67 & $\mathrm{Cc}$ & 23,34 \\
\hline 20 & 3,95 & Ac & 23,84 & 2,37 & $\mathrm{Ba}$ & 37,69 & 2,74 & $\mathrm{Ba}$ & 28,82 & 2,31 & $\mathrm{Bb}$ & 18,93 \\
\hline 30 & 2,69 & ABde & 19,74 & 2,52 & $\mathrm{Ba}$ & 30,66 & 2,38 & Babc & 29,31 & 3,10 & $\mathrm{Aa}$ & 19,69 \\
\hline 35 & 2,34 & Bfe & 21,36 & 2,54 & $\mathrm{Ba}$ & 30,79 & 2,10 & $\mathrm{Bbc}$ & 27,26 & 3,14 & $\mathrm{Aa}$ & 29,01 \\
\hline 40 & 2,13 & BCfe & 24,05 & 2,58 & $\mathrm{Ba}$ & 33,12 & 1,90 & $\mathrm{Cc}$ & 24,91 & 3,18 & $\mathrm{Aa}$ & 33,59 \\
\hline 45 & 1,96 & $\mathrm{Bf}$ & 25,29 & 2,67 & $\mathrm{Aa}$ & 36,43 & 1,82 & $\mathrm{Bc}$ & 25,86 & 3,15 & $\mathrm{Aa}$ & 36,23 \\
\hline 50 & 1,87 & $\mathrm{Bf}$ & 26,34 & 2,77 & $\mathrm{Aa}$ & 37,42 & 1,82 & $\mathrm{Bc}$ & 30,03 & 3,09 & $\mathrm{Aa}$ & 36,44 \\
\hline
\end{tabular}

Tabela 1. Comparação das médias* da RSP (MPa) em função dos tratamentos, em diferentes profundidades

* Médias seguidas das mesmas letras maiúsculas nas colunas e minúsculas nas linhas, não diferem estatisticamente pelo teste de Tukey em $5 \%$ de probabilidade

** 0 s tratamentos 1, 2, 3 e 4 referem-se, respectivamente, ao solo textura argilosa 2 cortes, solo textura argilosa 4 cortes, solo textura média 2 cortes e solo textura média 4 cortes 
para a experimentação agrícola valores de coeficiente de variação acima de $20 \%$ são considerados altos.

Outra camada significativa muito diferente na avaliação das pressões sobre o solo é a segunda camada de $10 \mathrm{~cm}$ de profundidade, em que o tratamento 1 apresentou diferença significativa entre os quatro tratamentos estudados com valor médio de RSP de 5,79 MPa.

Evidencia-se, portanto, que o tipo de solo e o número de cortes influenciam sobremaneira os resultados que se pode obter com o manejo da cultura, uma vez que o tráfego de máquinas e equipamentos neste sistema de produção é intensivo, pelo fato de se tratar de uma cultura semiperene tendo em média cinco cortes antes da renovação do canavial.

Os solos mais arenosos estão sujeitos a maior compactação nas maiores profundidades, em virtude da deposição das partículas de menor diâmetro, fato este que pode ser observado nos dados obtidos nos tratamentos 3 e 4; comparando-se os diferentes tratamentos, vê-se que o maior valor de densidade para o solo textura média foi $1,94 \mathrm{~g} \mathrm{~cm}^{-3}$ e, no solo textura argilosa, $1,51 \mathrm{~g} \mathrm{~cm}^{-3}$ (Figura 1); esta diferença está relacionada ao tipo de solo que apresenta maior compacidade em função do teor de umidade, conforme observado por Novak et al. (1987), quando verificaram que os valores de densidade global acima dos quais o crescimento radicular pode ser prejudicado, não são os mesmos para todos os solos. Valores acima de 1,7 a 1,8 $\mathrm{g} \mathrm{cm}^{-3}$ para solo arenoso e de 1,5 a 1,7 $\mathrm{g} \mathrm{cm}^{-3}$ para solos argilosos têm causado sérios problemas.

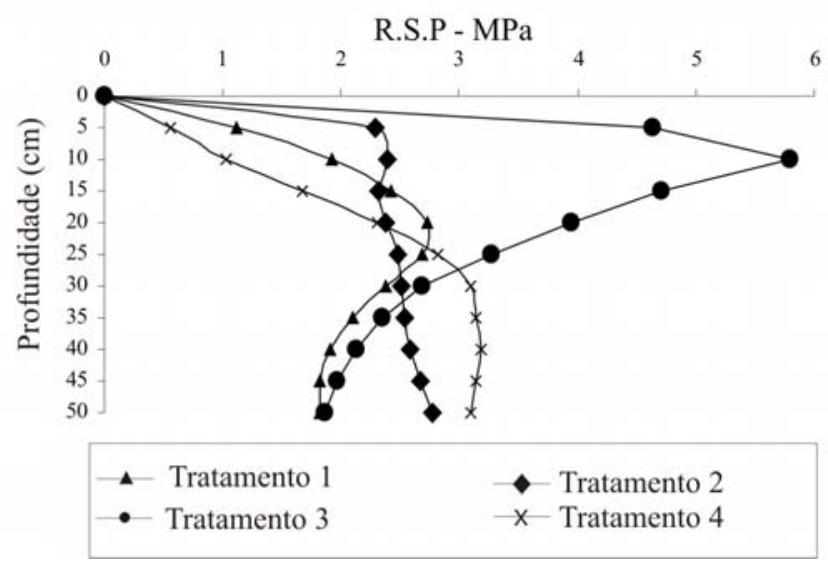

Figura 2. Curvas de resistência do solo a penetração (RSP) para os dois tipos de solo e número de cortes.

Uma análise importante em cada tratamento está relacionada com a variabilidade dentro do perfil de cada solo estudado em seus níveis de corte. No tratamento 1 é possível observar a redução gradativa da RSP à medida que vai se aprofundando no perfil do solo. Os maiores níveis de RSP estão na profundidade de até $25 \mathrm{~cm}$, sendo $10 \mathrm{~cm}$ a faixa que apresenta a maior resistência do solo a penetração. Na camada de $25 \mathrm{~cm}$ a $50 \mathrm{~cm}$ os valores decrescem, sendo esta faixa significativamente diferente da camada até $25 \mathrm{~cm}$, evidenciando duas camadas distintas. Os dados de RSP abaixo dos níveis considerados críticos para o crescimento das raízes se encontravam a 45 e $50 \mathrm{~cm}$ de profundidade, respectivamente.

No tratamento 2 ocorreu o inverso, visto que houve tendência ao aumento de RSP nas camadas mais profundas. Embora as médias tenham sido estatisticamente iguais, entre as profundidades ocorrem valores menores nas camadas superiores, donde se esperava maiores níveis de RSP pela ocorrência de tráfego mais intenso, devido ao maior número de cortes.

Essas diferenças foram influenciadas provavelmente, pelos variados níveis de umidade no perfil do solo. No tratamento 2 a umidade foi 5,18\% maior que a umidade apresentada no tratamento 1, para a mesma profundidade $(0$ a $15 \mathrm{~cm})$, conforme dados da Tabela 2, concordando com Cassel et al. citados por Klein at al. (1998), que relatam a dependência dos resultados em relação ao teor de água e densidade do solo, o que dificulta a interpretação dos resultados.

Tabela 2. Umidade do solo de textura argilosa e média (\%)

\begin{tabular}{cccc}
\hline Tratamento * $^{*}$ & \multicolumn{3}{c}{ Profundidade (cm) } \\
\cline { 2 - 4 } & $\mathbf{0}$ a $\mathbf{1 5}$ & $\mathbf{1 5}$ a $\mathbf{3 0}$ & $\mathbf{3 0}$ a $\mathbf{4 5}$ \\
2 & 18,71 & 21,05 & 21,70 \\
3 & 23,89 & 22,20 & 20,05 \\
4 & 5,14 & 5,12 & 5,27 \\
\hline
\end{tabular}

* Tratamentos 1 e 2 - solo de textura argilosa, tratamento 3 e 4 - solo de textura média

No tratamento 2 ficou evidenciada a influência do teor de água nos resultados de RSP, pois as diferenças nos valores de umidade na camada de 0 a $15 \mathrm{~cm}$ são maiores que nas camadas inferiores de 15 a 30 e 30 a 45 cm; já na camada de 30 a $45 \mathrm{~cm}$, a umidade do tratamento 1 foi muito próxima à do tratamento 2, em que os valores de RSP foram maiores, indicando maior compactação nas camadas inferiores, sugerindo que maior tráfego implica em maior compactação, mesmo nas camadas mais profundas, em razão do efeito cumulativo da pressão vertical provocada pelos pneus dos veículos de transporte (Mantovani, 1987).

No tratamento 2, apesar dos valores de RSP em todas as profundidades não terem apresentado diferenças estatísticas significativas, os mesmos estiveram acima do nível crítico (2,0 MPa) para o crescimento das raízes, considerando-se as citações para outras culturas. Caso a umidade da camada superficial estivesse próxima dos valores do tratamento 1 , os valores de RSP seriam, provavelmente maiores, indicando também maior compactação, em que ocorreu maior movimentação de máquinas e caminhões no processo de colheita da cana-de-açúcar.

Observa-se no tratamento 3, a tendência do aumento progressivo de RSP até $25 \mathrm{~cm}$ de profundidade, invertendo-se logo a seguir. O maior valor de RSP foi a $20 \mathrm{~cm}$, mas até a profundidade de $35 \mathrm{~cm}$ os valores de RSP estavam acima de 2,0 MPa, prejudicial ao desenvolvimento do sistema radicular, de acordo com Taylor et al. (1966).

Na camada de 5 a $10 \mathrm{~cm}$ de profundidade os valores de RSP diferiram estatisticamente entre si e se apresentaram abaixo do nível crítico, sem dúvida por causa dos cultivos efetuados na soqueira e pelas características do solo, que apresentou maior 
teores de areia, como também por se tratar da camada que sofre maior movimentação no cultivo da cana-de-açúcar.

Na faixa mais profunda, de 35 a $50 \mathrm{~cm}$, os valores foram menores que 2,0 $\mathrm{MPa}$, diferindo das demais profundidades. Neste tratamento, o teor de água foi homogêneo ao longo do perfil do solo, e a maior diferença foi de 0,15 pontos percentuais, indicando que, praticamente, não houve interferência desse parâmetro nos valores de resistência do solo a penetração (Tabela 2).

No tratamento 4 a camada com RSP maior que 2,0 $\mathrm{MPa}$, foi encontrada na faixa de 20 a $50 \mathrm{~cm}$ de profundidade, com as médias variando de 2,31 a 3,18 MPa; ainda no mesmo tratamento, os teores de água no solo decresceram ao longo do perfil, o que pode ter influenciado nos valores de RSP, apresentando a mesma tendência do tratamento 2. A maior resistência pode também estar correlacionada com o carreamento das partículas mais finas das camadas superiores que se vão acumulando mais abaixo, o qual pode ter maximizado a RSP, de vez que a maior porosidade nesses solos pode ter permitido um rearranjo dessas partículas nas camadas inferiores. Nos tratamentos ficou evidenciada a influência do teor de água nos resultados de resistência do solo a penetração.

Como a formação e o crescimento das raízes são prejudicados pelas características do solo, os valores de resistência encontrados acima de 2,0 MPa podem provocar menor crescimento do sistema radicular, prejudicando o crescimento da planta nos períodos mais críticos de disponibilidade de água, tendo em vista que a disponibilidade de água diminui da camada mais superficial até a mais profunda.

Para avaliação da variabilidade espacial, foram estudados dois parâmetros, a RSP em todos os tratamentos e em 10 profundidades (de $5 \mathrm{em} 5 \mathrm{~cm}$ ), e a umidade nas faixas de 0 a $15 \mathrm{~cm}$, 15 a $30 \mathrm{~cm}$ e 30 a $45 \mathrm{~cm}$. Nas diversas profundidades, as avaliações foram feitas pelo fato de terem apresentado valores diversos de resistência do solo a penetração, com comportamento diferenciado nos dois tipos de solo e nos dois níveis de corte. O teor de água também apresentou valores diferenciados para os dois tipos de solo e nas 10 profundidades estudadas.

Adotando-se os mesmos critérios apresentados por Couto (1997), a seleção dos semivariogramas obedeceu à sistemática do componente aleatório, no qual a relação entre o efeito pepita (Co) e o componente C (variância estrutural) que compõe o patamar $(\mathrm{Co}+\mathrm{C})$ fosse representativo de um erro com significância menor que 0,5.

Elaboraram-se 40 semivariogramas, mas apenas quatro, ou seja, $10 \%$ do total apresentaram modelo, porém se observou que isto não tem relação com o coeficiente de variação das profundidades, pois o tratamento que apresentou o me- nor valor de CV foi o que obteve maior valor de alcance, corroborando com o observado por Couto (1997).

Os modelos foram escolhidos tendo-se como critério o valor e < 0,5 (Eq. 2). Na Tabela 3 têm-se os modelos que se ajustaram às exigências de dependência espacial dos dados amostrados para a RSP.

Observando-se os semivariogramas, percebe-se que os fatores que interferem na RSP não agem de forma similar em todas as profundidades. Verificou-se que o solo textura argilosa apresentou número maior de modelos quando comparado com o solo de textura média, mostrando maior correlação na dependência espacial dos dados que no solo de textura média, e isto é corroborado por outros pesquisadores, como Prevedello (1987) e Maia (1999).

A Figura 3 representa o semivariograma, com modelo esférico dos dados de RSP para a profundidade de $10 \mathrm{~cm}$ do tratamento 1 (S1) e o semivariograma modelo exponencial
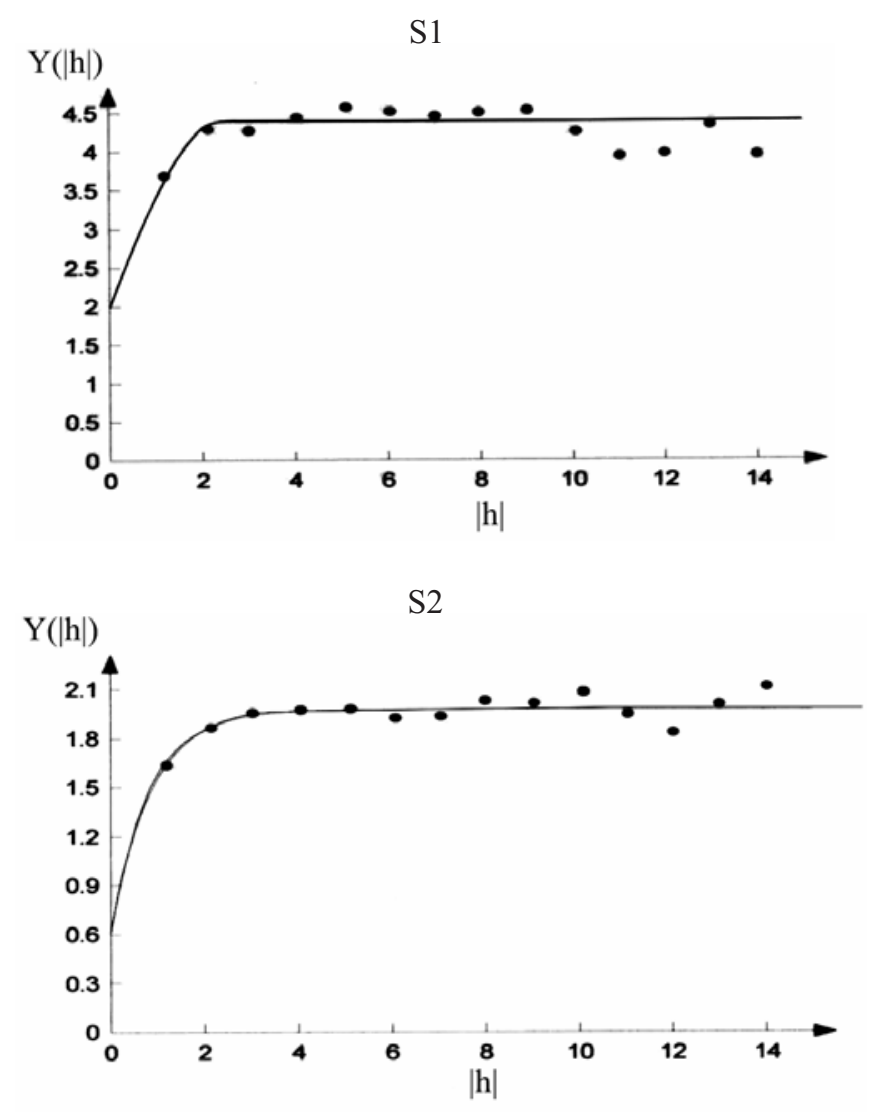

Figura 3. Semivariograma modelo esférico da RSP no tratamento 1 a $10 \mathrm{~cm}$ de profundidade (S1) e modelo exponencial da RSP no tratamento 1 a $15 \mathrm{~cm}$ de profundidade (S2).

Tabela 3. Dados dos semivariogramas selecionados com valores de e $<0,5$.

\begin{tabular}{|c|c|c|c|c|c|c|c|}
\hline Tratamento & Profundidade & Parâmetro & Modelo & Co & C & $\mathbf{R}$ & $e=C_{0} / C$ \\
\hline 1 & 10 & RSP & Esférico & 1,9778 & 4,3859 & 2,40 & 0,4509 \\
\hline 1 & 15 & RSP & Exponencial & 0,5938 & 1,9739 & 2,55 & 0,3008 \\
\hline 1 & 25 & RSP & Exponencial & 0,2299 & 0,4749 & 3,14 & 0,4841 \\
\hline 4 & 15 & RSP & Esférico & 0,0399 & 0,1520 & 1,94 & 0,2625 \\
\hline 3 & 45 & UM & Esférico & 0,1520 & 0,3080 & 2,55 & 0,4935 \\
\hline 2 & 30 & UM & Esférico & 2,4636 & 5,5996 & 2,10 & 0,4399 \\
\hline
\end{tabular}


da RSP no tratamento 1 a $15 \mathrm{~cm}$ de profundidade (S2). Temse que o alcance obtido por este último modelo mostra distância de 2,4 m, valor muito próximo do mesmo solo e corte a $15 \mathrm{~cm}$ de profundidade; a distância nos pontos observados foi em uma malha de 1,40 por 1,00 m, sendo menor que o do alcance obtido nos semivariogramas, indicando que as tomadas de pontos ocorreram dentro de um intervalo confiável.

O maior valor de $\gamma(\mathrm{h})$ ocorreu no tratamento 1 , na profundidade de $25 \mathrm{~cm}$ (S3), com alcance de 3,14 m, indicando que as variáveis estavam menos associadas que nos outros tratamentos. O inverso desta proposição ocorreu no tratamento 4 , na profundidade de $15 \mathrm{~cm}$ (S4), em que o valor do alcance foi de $1,94 \mathrm{~m}$, indicando maior associação dos valores observados (Figura 4).

O interesse da análise não se limitou à obtenção de um modelo de dependência espacial, mas também, em predizer valores em pontos não amostrados. A krigagem permitiu a interpolação, em que uma malha de comportamento da variável na região pôde ser visualizada por meio de um mapa de isolinhas ou desenho de uma superfície.

Para as profundidades que apresentaram modelo, fezse a krigagem para melhor visualização dos valores analisados.

Conforme a Figura 5 nota-se tendência dos locais que apresentaram maior RSP (conforme a escala de cores) de
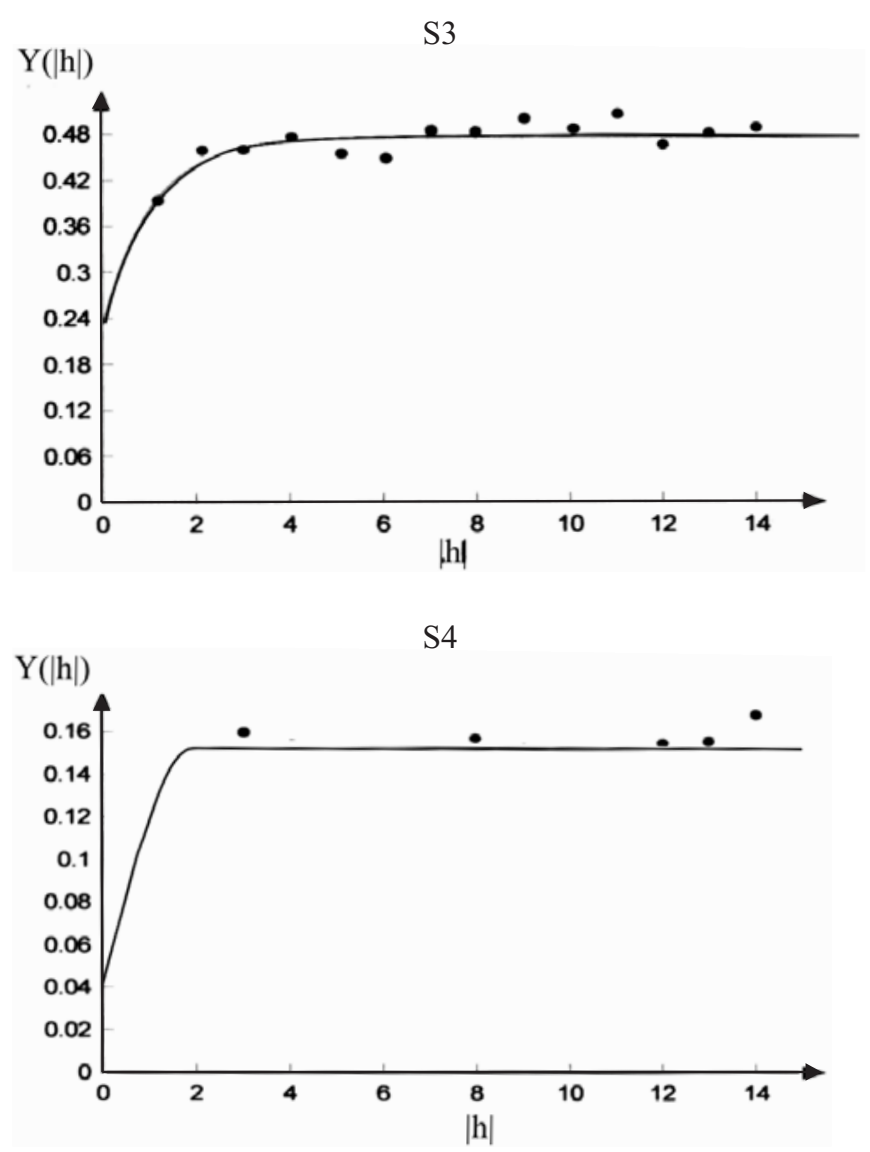

Figura 4. Semivariograma modelo exponencial da RSP no tratamento 1 a $25 \mathrm{~cm}$ de profundidade (S3) e modelo esférico da RSP no tratamento 4 a $15 \mathrm{~cm}$ de profundidade (S4)

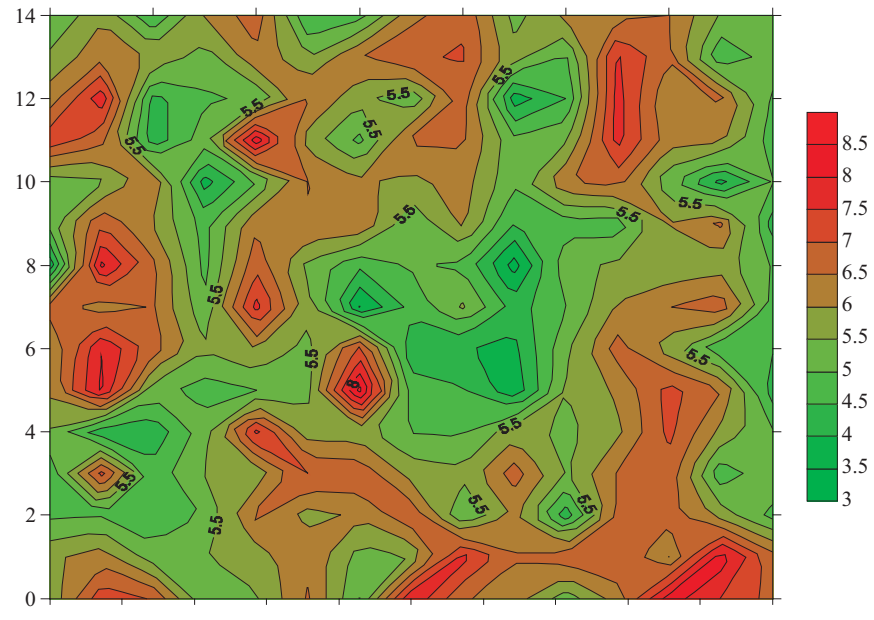

RSP 1

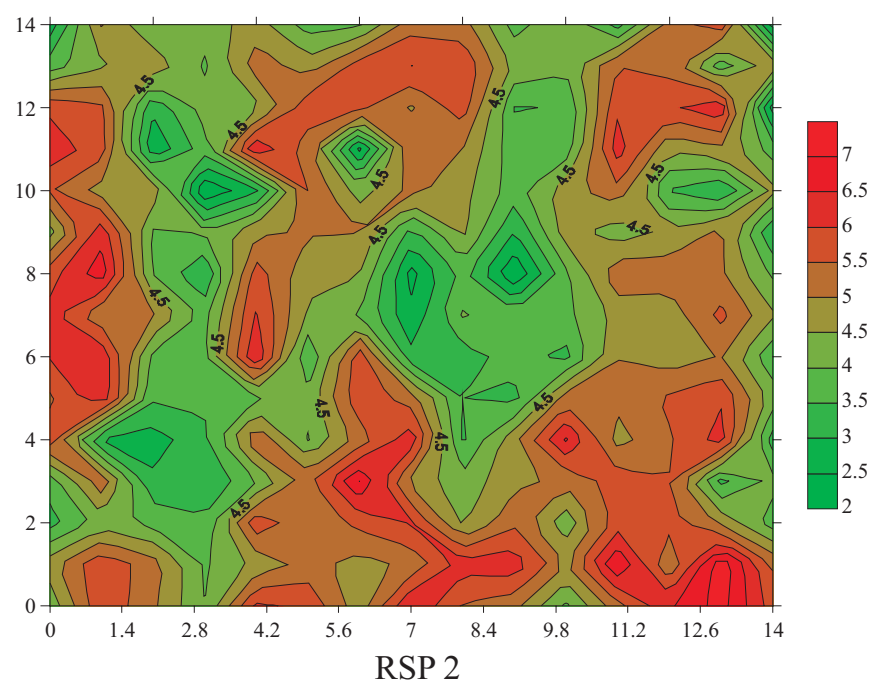

Figura 5. Distribuição espacial da RSP (MPa) no tratamento 1 a $10 \mathrm{~cm}$ de profundidade (RSP 1) e no tratamento 1 a $15 \mathrm{~cm}$ de profundidade (RSP 2)

coincidirem com as linhas de número um e cinco, em que a cada ano, se repetiu o tráfego de veículos de transporte. Observa-se também que, as áreas que indicaram menor RSP foram mais concentradas fora das linhas de ação onde trafegam máquinas e equipamentos, resultados similares aos encontrados por Tormena \& Roloff (1996). O mapa do tratamento 1 a $15 \mathrm{~cm}$ de profundidade (RSP 2), apresentou a mesma tendência de resistência que a profundidade anterior, apesar de mostrar valor máximo menor que a profundidade de $10 \mathrm{~cm}$, indicando a mesma tendência de compactação.

No tratamento 1 a $25 \mathrm{~cm}$ (RSP 3) de profundidade (Figura 6), se observa que nas regiões onde os valores de RSP foram maiores, as isolinhas apresentaram a mesma tendência das anteriores, porém com menor intensidade, indicando menor influencia da pressão sobre o solo, apesar do valor máximo ter sido superior a 2,0 $\mathrm{MPa}$.

O tratamento 4, apresentou apenas um modelo a $15 \mathrm{~cm}$ (RSP 4). Nota-se que a tendência de maior compactação se encontra mais ao lado direito da parcela, porém com a mesma tendência dos maiores valores se acharam na faixa de trânsito dos veículos de transporte. 


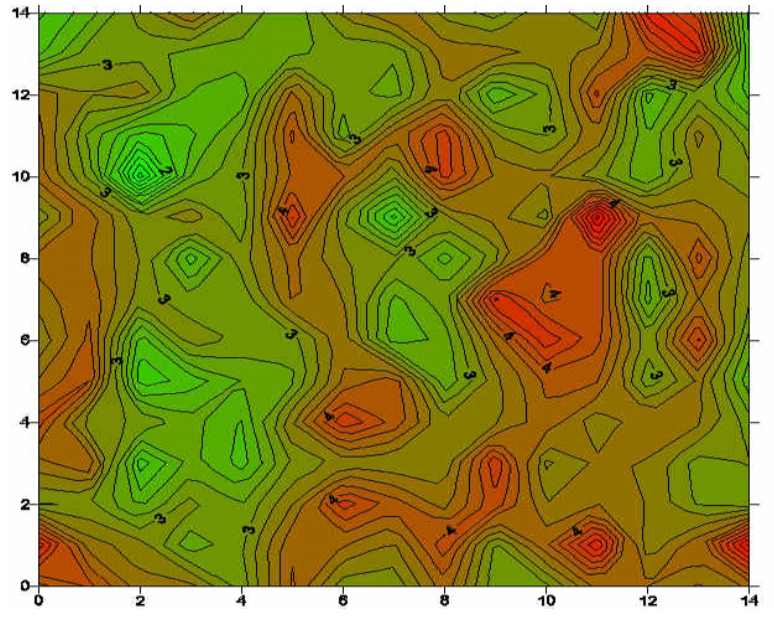

RSP 3

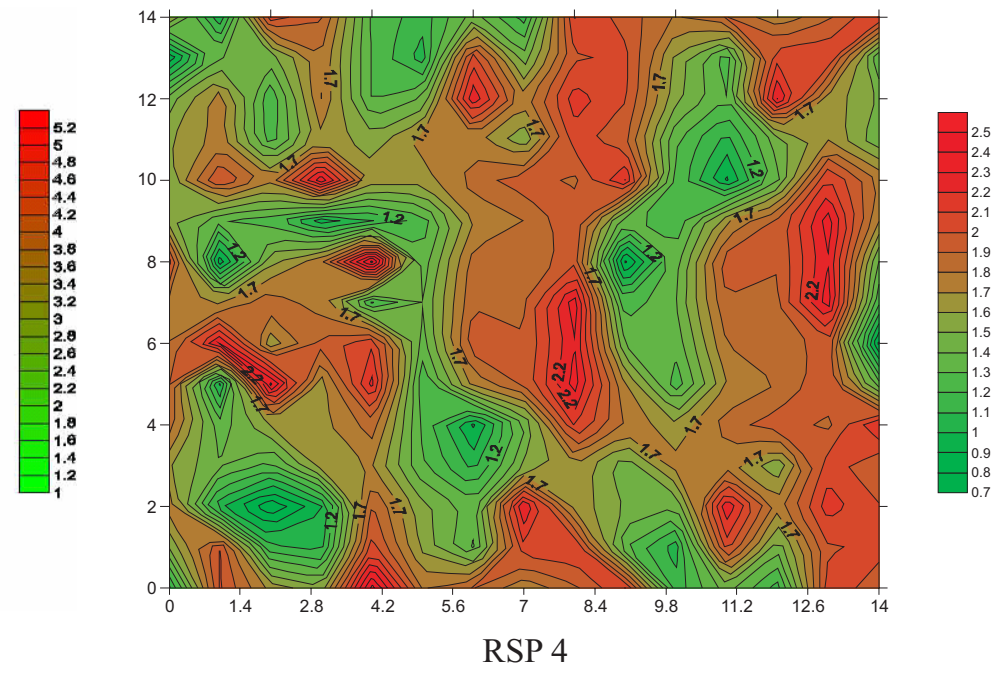

Figura 6. Distribuição espacial da RSP (MPa) no tratamento 1 a $25 \mathrm{~cm}$ de profundidade (RSP 3) e distribuição espacial da RSP (MPa) no tratamento 4 a $15 \mathrm{~cm}$ de profundidade (RSP 4)

O ideal para este tipo de estudo seria identificar a forma mais prática e econômica de preparo do solo, com fins de eliminar a compactação por meio do mapa de isolinhas, porém se percebe que os valores de resistência são muito variáveis ao longo do perfil do solo, visto que os coeficientes de variação são altos e muitos fatores podem interferir na leitura de resistência indicando que, mesmo se ocorrer a repetição de pressão no solo e nos mesmos locais, não haverá dependência espacial em nenhuma profundidade, pois a deformação no solo é muito variável.

Observou-se, também, que nem todos os perfis que apresentaram os maiores valores de resistência do solo a penetração indicaram modelo, sendo difícil um modelo de preparo baseado neste tipo de análise.

O teor de água, conforme mostra a Tabela 2, variou com o tipo de solo e com a profundidade, em maior ou menor grau. Segundo Mantovani (1987), o teor de água na RSP é um indicador secundário de compactação, não sendo medição física direta de qualquer condição do solo, devendo ser correlacionada com RSP. Para o teor de água foram dois modelos de semivariograma, 16,7\% do total. Na Figura 7 está o semivariograma para o tratamento 3 a $45 \mathrm{~cm}$ de profundidade (S 5), no qual o alcance foi de 2,10 m, com valor de $\gamma$ (h) bastante baixo, indicando alta associação entre as variáveis e o semivariograma para o tratamento 4 a $45 \mathrm{~cm}$ de profundidade (S6), apresentando um valor de alcance muito próximo do anterior, mas com valor de $\gamma$ (h) elevado.

Embora o teor de água nesse tratamento não tenha diferenciado muito ao longo do perfil, somente a camada mais profunda apresentou modelo de dependência espacial e conforme o mapa da Figura 8 (TA 1), os maiores valores do teor de água se encontram mais ao centro da parcela, não indicando um comportamento de distribuição correlacionado com as faixas de maior intensidade de tráfego dos veículos de transporte.

Segundo os dados da Figura 8 (TA 2), houve pouca variabilidade nos teores de água na parcela, mostrando maior homogeneidade que o tratamento anterior, sendo que os maiores valores estavam em circunferências pontuais, dentro da área avaliada.

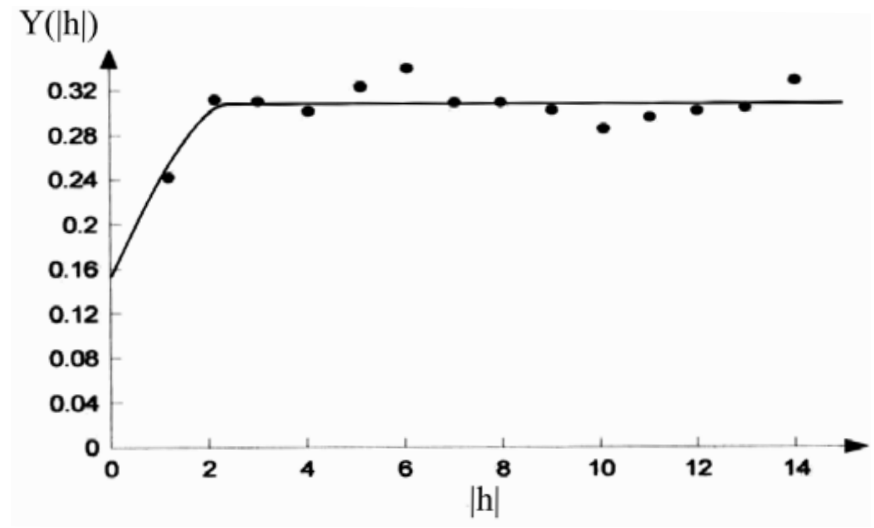

S5

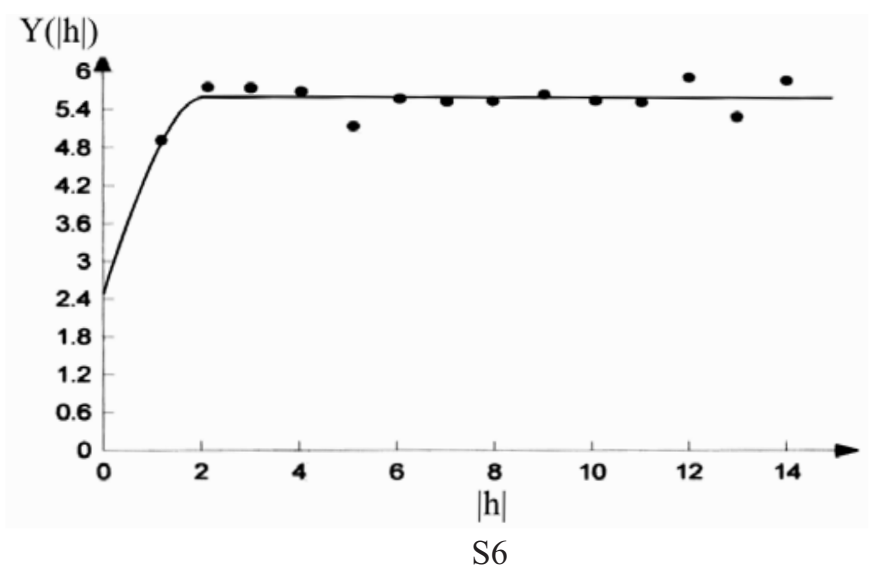

Figura 7. Semivariograma modelo esférico do teor de água do solo no tratamento 3 a $45 \mathrm{~cm}$ de profundidade (S 5) e no teor de água no tratamento 4 a $45 \mathrm{~cm}$ de profundidade (S 6) 

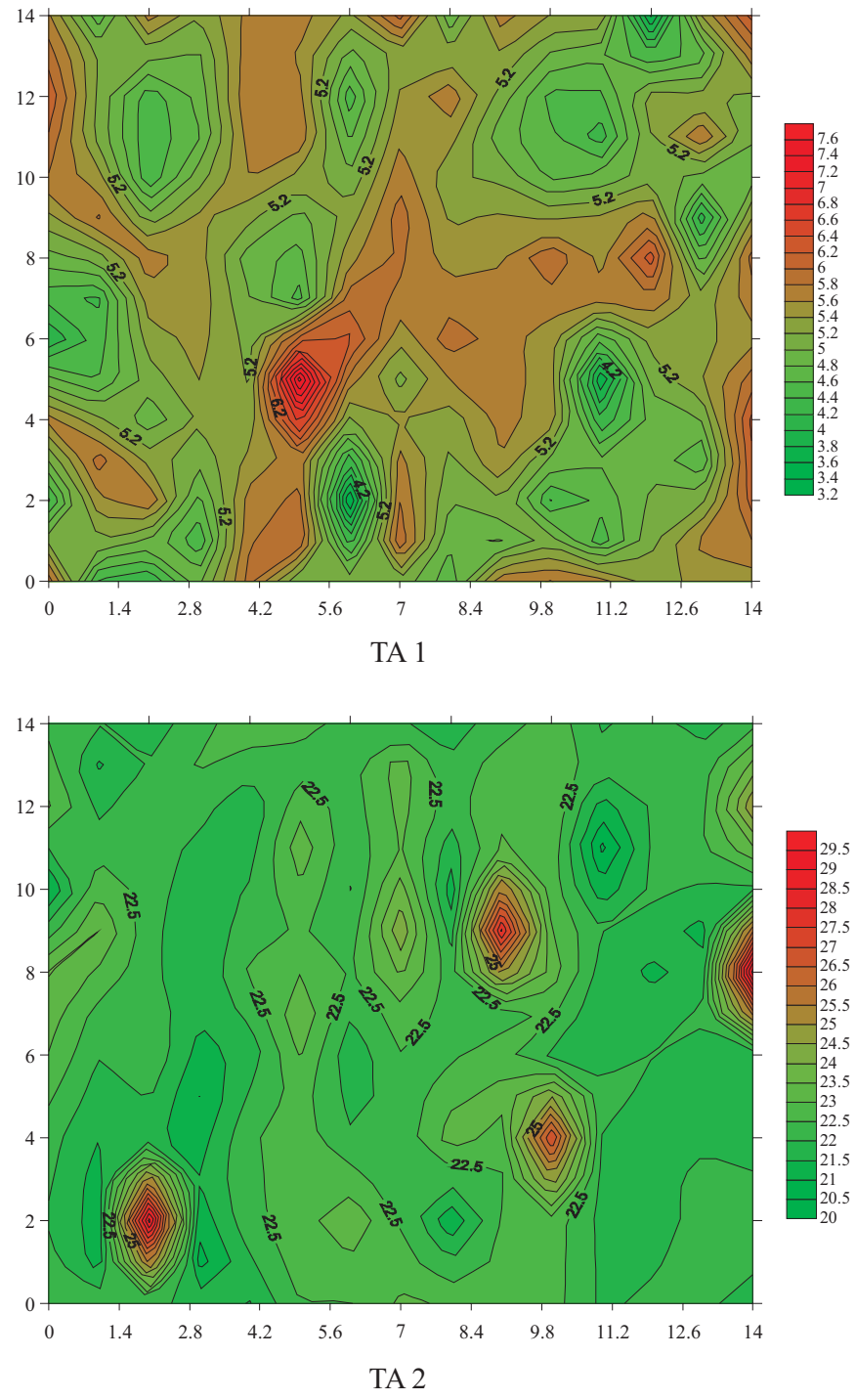

Figura 8. Distribuição espacial teor de água (\%) no tratamento 3 a $45 \mathrm{~cm}$ de profundidade (TA1) e no tratamento 2 a $30 \mathrm{~cm}$ de profundidade (TA 2)

\section{CONCLUSÕES}

1. A RSP foi dependente do tipo de solo e do número de corte.

2. O solo com maior teor de areia foi mais compassível com teores de água inferiores.

3. O maior número de tráfego levou a compactação a profundidades maiores.

4. Foi possível visualizar as isolinhas de maior compactação por meio dos mapas de krigagem nos tratamentos que ofereceram modelos, indicando, assim, onde houve maior trânsito nas linhas de cana.

\section{LITERATURA CITADA}

Couto, E. G. Variabilidade espacial de propriedades do solo influenciadas pela agricultura em escala regional e local no sul do Estado de Mato Grosso. Porto Alegre: UFRGS, 1997. 178p. Tese Doutorado

EMBRAPA - Empresa Brasileira de Pesquisa Agropecuária. Sistema brasileiro de classificação de solo. Rio de Janeiro: CNPS. 1999. 412p.

EMBRAPA - Empresa Brasileira de Pesquisa Agropecuária. Manual de métodos de analise de solos. 2.ed. Rio de Janeiro: CNPS. 1997. 212p.

Ferreira, D. F. Análises estatísticas por meio do SISVAR para Windows versão 4.0. In: Reunião Anual da Região Brasileira da Sociedade Internacional de Biometria, 45. São Carlos, 2000. Programas e Resumos... São Carlos: UFSCar, 2000. 235p.

Klein, V. A.; Flibardi, P. L.; Silva, A. P. Resistência a penetração sob diferentes condições de densidades e teores de água. Engenharia Agrícola, Jaboticabal, v.18, n.2, p.45-54, 1998.

Köppen, W. P. Climatologia, com um estúdio de los climas de la tierra. México: Fundo de Cultura Econômica, 1948. 478p.

Letey, J. Relationship between soil physical properties and crop production. Advances in Soil Science. New York, v.1, p.277294, 1985.

Maia, J. C. Determinação de esquemas de amostragem para avaliação de propriedades físicas do solo sob diferentes sistemas de preparo. Campinas: UNICAMP, 1999. 158p. Tese Doutorado

Mantovani, E. C. Compactação do solo. Informe Agropecuário, Belo Horizonte, v.13, n.147, p.52-53, 1987.

Novak, L. R.; Montovani, E. C.; Martyn, P. J.; Fernandes, B. Efeito do tráfego de tratores da pressão de contato pneu/solo na compactação de um Latossolo Vermelho Escuro álico, em dois níveis de umidade. Pesquisa Agropecuária Brasileira, Brasília, v.27, n.12, p.1587-1595, 1987.

Pimentel, F. G. Curso de estatística experimental. Piracicaba: ESALQ/USP, 1987. 467p.

Prevedello, B. M. S. Variabilidade espacial de parâmetros de solo e planta. Piracicaba: ESALQ/USP, 1987. 165p. Tese de Doutorado

Rosolem, C. A. Interpretação de análise de solo e desenvolvimento radicular da cana-de-açúcar. In: Seminário sobre Tecnologias de Manejo de Solo e Adubação da Cana-de-Açúcar, 1, 1994, Ribeirão Preto. Anais...Ribeirão Preto: p.53-73. 1994.

Taylor, H. M.; Roberson, G. M.; Parker Jr., J. J. Soil strength-root penetration relations to medium to coarse-textured soil materials. Soil Science, Baltimore, v.102, p.18-22, 1966.

Tormena, C. A.; Roloff, G. Dinâmica da resistência a penetração de um solo sob plantio direto. Revista Brasileira Ciência do Solo, Campinas, v.20, n.2, p.333-339, 1996.

Weaich, K.; Bristow, K. L.; Cass, A. Preemergent shoot growth of maize under different drying conditions. Soil Science Society of American Journal, Madison, v.56, p.1272-1278, 1992. 